\title{
Variation and change in English varieties of British Sign Language ${ }^{i}$
}

\author{
Adam Schembri, Rose Stamp, Jordan Fenlon and Kearsy Cormier
}

British Sign Language (BSL) is the language used by the deaf community in the United Kingdom. In this chapter, we describe sociolinguistic variation and change in BSL varieties in England. This will show how factors that drive sociolinguistic variation and change in both spoken and signed language communities are broadly similar. Social factors include, for example, a signer's age group, region of origin, gender, ethnicity, and socio-economic status (e.g., Lucas, Valli \& Bayley 2001). Linguistic factors include assimilation and co-articulation effects (e.g., Schembri et al. 2009; Fenlon et al. 2013).

It should be noted, however, some factors involved in sociolinguistic variation in sign languages are distinctive. For example, phonological variation includes features, such as whether a sign is produced with one or two hands, which have no direct parallel in spoken language phonology. In addition, deaf signing communities are invariably minority communities embedded within larger majority communities whose languages are in another entirely different modality and which may have written systems, unlike sign languages. Some of the linguistic outcomes of this contact situation (such as the use of individual signs for letters to spell out written words on the hands, known as fingerspelling) are unique to such communities (Lucas \& Valli 1992). This picture is further complicated by patterns of language transmission which see many deaf individuals acquiring sign languages as first languages at a much later age than hearing individuals (e.g., Cormier et al. 2012).

\section{The deaf community in England}

The prevalence of deafness in developed societies has long been estimated to be about 0.1 percent of the population (i.e., one in a thousand people) (Schein 1968). If this were the case, one would expect the deaf community in England to number approximately 50,000 people. The 2011 Census for England and Wales ${ }^{\mathrm{ii}}$ reported 22,000 thousand sign language users, however, with some $70 \%$ of these (i.e., 15,000) explicitly identifying BSL as their primary sign language. These figures have been disputed, however, because it is not clear how many deaf people with lower levels of 
literacy would have answered these questions accurately. As a result, the British Deaf Association's website gives an estimate of 73,000 deaf BSL users in England alone (https://www.bda.org.uk/bsl-statistics). Some research indicates that there may be fewer people with severe and profound deafness in the populations of developed nations than has previously been assumed (e.g., Johnston 2004), so it may be that the Census figures are reasonably accurate after all.

Regardless of the varying estimates of its size, the signing deaf population in England forms a thriving, cohesive community (Ladd 2003). National and local deaf social and sporting clubs and associations are active in all the major urban centres, along with a range of welfare organisations specifically offering services to signing deaf people.

\section{The history of BSL}

The origins of BSL are unknown, as there are relatively few early records of sign language use in England (although many in comparison with other sign languages). BSL nevertheless may be assumed to be a relatively 'old' language when compared to many of the sign languages that have been identified in other parts of the world. For example, Taiwan Sign Language dates back to only the late nineteenth century (Smith 1989), and Israeli Sign Language from the early twentieth century (Aronoff et al. 2003). In contrast, there is some evidence of links between BSL and varieties of signing used in England during the seventeenth century, as we explain below.

The earliest references to sign language use in England date from the sixteenth century, although there is no evidence to link these with BSL as it subsequently developed (Jackson 1990). These include a report of signed communication used between deaf friends Edward Bone and John Kempe in Richard Carew's History of Cornwall (1602). None of these early references, however, provide any formational descriptions of signs or of sign language grammar.

Figure 1. Two signs described by Bulwer (1648) that are still used in BSL today 


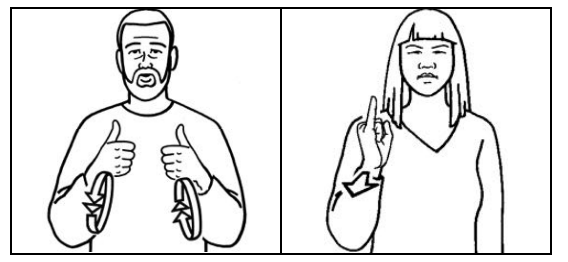

CONGRATULATE

BAD

Amongst the earliest records which describe the sign language(s) in use in seventeenth-century England are two books by John Bulwer, Chirologia and Philocophus, published in 1644 and 1648 respectively (Bulwer 1644, 1648). The latter book was dedicated to a baronet and his brother, both of whom were deaf. Bulwer provided mostly written descriptions of the signs used by the deaf brothers, and some seem to closely resemble signs with a related form and meaning used in BSL today, such as GOOD, BAD, WONDERFUL, SHAME, CONGRATULATE and JEALOUs ${ }^{\mathrm{iii}}$ (see Figure 1).

A number of other written sources make it clear that some deaf people were using forms of sign language before the first schools and institutions for the deaf opened in England. In the novel The Life and Adventures of Mr. Duncan Campbell, Deaf Mute, Daniel Defoe mentioned that signs and fingerspelling (the use of a manual alphabet to spell out English words on the hands) were widely used by deaf people in the early eighteenth century (Woll 1987). The famous diarist, Samuel Pepys, described an encounter with a deaf servant who reported to his master, George Downing, of the Great Fire of London in 1666 using signing (Stone \& Woll, 2008).

The more widespread use of signed communication among English deaf people, however, most certainly began during the industrial revolution starting around the 1750s. The resulting population explosion and the mass migration to cities led to a significant increase in the number of deaf children in urban centres, and this seems to have played a significant role in the introduction of public education for deaf children (Johnston 1989). The first British school for deaf children (and perhaps the first school of its kind in the world) was opened in 1760 by Thomas Braidwood in Edinburgh, in the same year that Abbe Charles-Michel de l'Épée (widely considered the father of deaf education) established his institution in Paris (Jackson 1990). It is likely, in a similar way to recent reports of the impact of the establishment of deaf education on deaf people in Nicaragua (Kegl, Senghas \& Coppola 1999), that these 
educational institutions created the first environment for a deaf community and BSL to develop in England.

By 1870, some 22 schools for the deaf had been established in the UK (Kyle \& Woll 1985). Most of these were residential. The existence of these schools supported the creation and consolidation of the deaf community in England and of modern BSL. Many schools were set up by former pupils and teachers (who were themselves deaf) who graduated from other previously established schools.

\section{BSL in the twentieth century}

The use of signs and fingerspelling continued to varying degrees in English schools for deaf children into the twentieth century, but there was also an increased emphasis on teaching students to speak and lip-read (Kyle \& Woll 1985). This was increasingly true after the Milan International Congress of Educators of the Deaf in 1880 where the majority of teachers called for a ban on the use of signed communication in the classroom and demanded purely oral methods of instruction. School records from this period show falling numbers of deaf teachers of the deaf, and a decreasing reliance on signs in teaching (Brennan 1992). Sign language, however, certainly continued to be used in dormitories and playgrounds.

In the early to mid twentieth century, educational methodologies in England became increasingly focused on the sole use of spoken English as a medium of instruction. Following changes in educational philosophies in the 1960s, the emphasis shifted to 'normalising' the education of deaf children as much as possible, and residential schools began to scale down or close. By the 1980s, deaf children were increasingly integrated into classes with hearing children or attended classes in small units attached to regular schools. The increase in mainstreaming and closure of centralised, residential schools for deaf children meant that many deaf children did not have children from deaf families or deaf ancillary staff as linguistic role models (Ladd 2003).

Despite the many changes in approaches to the education of deaf children over the last two centuries, it seems that BSL has remained the primary or preferred language of the deaf community in England throughout much of that time. There can be little doubt, however, that the various educational philosophies which dominated deaf education over the last century - all of which have variously emphasised skills in 
signed, spoken, fingerspelled, and written English (with different degrees of success) rather than the use of natural sign languages - have had considerable impact on the transmission of BSL varieties within England.

\section{Sociolinguistic variation and change in English varieties of BSL}

The socio-historical circumstances of BSL varieties contribute to variation in usage, and this has served as the focus of a number of past and current studies of sociolinguistic variation in BSL (Deuchar 1981; Woll, Sutton-Spence \& Alsop 1991; Stamp et al., 2015). Each of these projects has focused on specific phonological, lexical, and syntactic variables that will be explored in the following sections. Variation in these linguistic features have been correlated to social characteristics, such as region, age, and gender.

\section{BSL Corpus Project}

Recent and on-going work on the sociolinguistics of BSL has drawn on data from the BSL Corpus Project ${ }^{\mathrm{iv}}$, so we will describe it here in some detail. The BSL Corpus Project, which began in 2008, was the first large-scale sociolinguistically-informed corpus project to be undertaken for BSL. The aim of the project was to create a corpus of elicited and spontaneous BSL digital video data from deaf native, near-native and early learners of BSL. The project has established an online, open-access video dataset available for researchers and the sign language community (Schembri et al. 2013), and has provided data for a number of studies thus far investigating sociolinguistic variation and change and language contact that will be explored in this chapter.

\section{Sites}

In order to obtain samples of regional variation, data were collected from eight sites across the UK: Belfast, Birmingham, Bristol, Cardiff, Glasgow, London, Manchester and Newcastle. These sites were selected because they are or were previously locations of a centralised school for deaf children, and because, as relatively large urban centres, it was assumed that they would provide a sufficiently large deaf community from which to recruit. 


\section{Participants}

Thirty participants were filmed at most sites, although slightly larger samples were collected in Bristol and London, with 32 and 37 participants respectively. In total, 249 deaf individuals were filmed. We attempted to recruit native and near-native signers, as well as early learners of BSL (cf., Lucas, Bayley \& Valli 2001) who were representative of the regional signs used in their particular region. Target participants were those who were British-born, were exposed to BSL before the age of seven years old and reported to have lived in the region where they were filmed for the last 10 years, but a small number of people who did not fit these criteria were included. Five individuals were not British-born and 12 reported learning BSL after age seven (all but one, however, learned BSL before age 12). Deaf participants were recruited by deaf community fieldworkers who were themselves native or fluent BSL signers and familiar with the local deaf community. Fieldworkers recruited local deaf people who they knew personally (e.g., friends, family, work colleagues) and who matched the project criteria. In recruitment we attempted to balance the sample for age groups, gender and social class and to represent deaf individuals from both deaf and hearing family backgrounds.

\section{Data collection}

The methodology for the BSL Corpus Project was based on two similar large-scale sociolinguistic investigations of ASL (Lucas, Bayley \& Valli 2001) and Auslan (Schembri et al., 2009) with some key differences. Unlike the other projects where groups of several participants were included, all British participants were filmed in pairs with another person from the same region and of a similar age (in London, one participant requested to be filmed a second time with a different partner). Four types of data were collected: a personal experience narrative, a free conversation of 30 minutes, responses to interview questions and to a lexical elicitation task.

\section{Lexical variation and change}

Lexical variation is significant in BSL varieties within England (with considerable variation in some core aspects of the lexicon), and was the focus of one of the first studies to emerge from the BSL Corpus project, so we will discuss it here. 


\section{Region}

Some of the existing regional variation in BSL lexis has been documented in the Dictionary of British Sign Language/English (Brien 1992) and in other publications (e.g., a book by Elton \& Squelch, 2009 on regional signs from London and the SouthEast), but compared to the lexicographic projects undertaken on closely related varieties of sign language in Australia (Johnston 1998), for example, lexical variation and its relation to region in BSL remains relatively poorly described. We do not yet have complete documentation of all existing regional vocabulary variants in the language, neither across the whole UK nor in England itself.

Data collected as part of the BSL Corpus Project was influenced by the first research on regional variation in BSL which was carried out at the University of Bristol by Woll, Allsop and Sutton-Spence (1991). This involved the collection of lexical variants from deaf BSL signers living in Glasgow, Newcastle, Manchester, London and Bristol. Flashcards with written English equivalents of the images displayed were used to elicit a set of signs from specific semantic fields including signs for colour terms, days of the week, and numbers. Signs for these concepts were known to vary greatly and in fact, the study showed that signs used in Glasgow for the days of the week MONDAY to SATURDAY are all completely different from signs used in the English cities. In England, these same signs are all lexicalised fingerspelled loans whereas in Glasgow, signs completely unrelated to fingerspelling are used. In this way, words from English can be borrowed into BSL (i.e., they can be incorporated into signing through fingerspelling as it allows for the manual spelling of English words). In the varieties of BSL in England (as opposed to Scotland), the fingerspelled sequence -M-M- is used for MONDAY, -T-T- for TUESDAY, T-H for THURSDAY, etc.

In attempting to account for regional lexical variation within BSL, it should not be assumed that there was a single homogeneous sign language (an 'Old BSL') from which the current lexical variants in England and other British varieties are historically derived. The variation is much more likely to be due to the fact that residential deaf schools were set up independently from each other in different parts of the UK during the nineteenth century. When these schools were established, there was no single, centralised training programme for teachers who wanted to use sign language in the classroom; thus the signs used within each school (by the teachers and 
by the students) must have varied from school to school. Furthermore, in many schools from the late nineteenth century, signed communication was forbidden in the classroom. This meant that there were no adult language models for those deaf children with hearing parents who do not sign, so this led to the creation of new signs by deaf children while using signed communication outside the classroom. Because sign languages must be used face to face, and because opportunities for travel were few, each variant tended to be passed down from one generation to the next without spreading to other areas. In a 1980 survey (Kyle \& Allsop 1982), for example, forty per cent of people surveyed in the Bristol deaf community claimed that they had rarely met a deaf person from farther than 125 miles away. Around half of the individuals in this study suggested that they could not understand the varieties of BSL used in areas in the UK beyond this distance.

Of course, the situation is very different today. Travel within England is much easier, and so signers more commonly come in contact with other regional variants. There is also regular signing on broadcast television in England, and regular interaction in BSL on the internet and using smartphones. Thus deaf people are now exposed to many more lexical variants of BSL than they once were. It appears that this may be the reason deaf people now report much less trouble communicating with those from distant regions of the country (Woll 1994). This greater contact between regional varieties appears to be leading to dialect leveling (Woll 1987; Stamp et al., 2014, 2015). There is in fact much controversy amongst sign language teachers surrounding the issue of dialect levelling and standardisation, with conflict arising between preserving traditional diversity within BSL and the notion of standardising signs for teaching purposes (e.g., Elton 2006).

The single largest investigation into BSL regional lexical variation drew on the BSL Corpus dataset (Schembri et al., 2013) using the lexical elicitation task data (which involved the elicitation of signs for 102 concepts from all 249 participants, using slides with an illustration and a prompt English word equivalent). The study by Rose Stamp and colleagues (Stamp et al., 2015) analysed variation and change in 41 lexical items in the following semantic domains: colours (brown, green, grey, purple, yellow), countries (America, Britain, China, France, Germany, India, Ireland and Italy), number signs for one to twenty and UK place-names (Belfast, Birmingham, Bristol, Cardiff, Glasgow, London, Manchester and Newcastle) $)^{\mathrm{v}}$. These specific concepts were selected on the basis of earlier work into variation (Woll, Allsop \& 
Sutton-Spence 1991), existing lexicographical information, as well as through consultations with native signers. The study produced a complex dataset, with considerable regional variation identified for almost all the signs elicited.

The UK place-name data were analysed to investigate anecdotal claims about their usage (Stamp et al., 2015). Such claims suggest that place-name signs may work to index local, in-group versus non-local, out-group identity. For example, it is claimed that Bristol signers use a different lexical variant for 'Bristol' than those living elsewhere. A total of 1992 tokens were classified as either local or non-local for the particular place-name analysed. The results revealed that, with the exception of signs meaning Glasgow, London and Manchester, the use of the local place-name variant significantly correlated with residency in that location. This means that residents of some cities were found to strongly favour the use of a local variant that was different to signs used to refer to that city by people from outside the community. For the English data, the effect was strongest in Newcastle, followed by Bristol and Birmingham.

It is not known to what extent BSL signers understand all the existing lexical variants, and how they respond to the signing produced by someone from a different region than their own. Stamp et al. (2016)'s study is the first of its kind on a sign language which aimed to investigate if regional differences led to some degree of lexical accommodation when BSL signers interact with signers from a different regional background. Twenty-five deaf participants in total were recruited from Belfast, Glasgow, Manchester, and Newcastle and paired with the same deaf conversational partner (who was from Bristol). Participants completed a 'spot-thedifference' task which was specifically designed to elicit regional variants. During the task, younger signers tended to accommodate more than older signers, by incorporating the regional sign used by their interlocutor in their own signing, but overall rates of accommodation were not high (around 14\% of all responses items exhibited some degree of lexical accommodation).

An interesting observation from this study was the fact that participants had few problems understanding one another during the task. In a follow-up study (Stamp, 2016), the same participants took part in a computer-based lexical recognition task in which they had to identify the meaning of 47 colour signs from various regions across the UK. The results indicate that overall signers had a poor knowledge of regional signs for colours when signs were presented in isolation and without mouthing (which 
involve the silent articulation of spoken language words while producing a lexically equivalent sign) of the equivalent English colour word. Signers with deaf parents performed better in the recognition task than signers with hearing parents, however, and varieties from London and Birmingham were easiest to recognise. The author suggests that this reflects the fact these signs are from two of the largest urban centres in England and are therefore the most widely known, and that signers who have been exposed to older varieties used by their deaf parents have enhanced knowledge of regional variation.

\section{Age}

As is well known, the vast majority of deaf people are born into hearing families and the age at which they acquire sign language may be delayed relative to hearing children's acquisition of spoken language. Thus the intergenerational transmission of BSL varieties is often disrupted. This can result in cross-generational differences, such that younger BSL signers sometimes report difficulty in understanding older signers. A study reported by Woll (1994), for example, showed that younger signers (i.e., those under 45 years of age) recognised significantly fewer lexical variants in BSL than older signers. An earlier study showed that the BSL colour signs BROWN, GREEN, PURPLE and YELLOW and numbers HUNDRED and THOUSAND used by older deaf people were not used by younger deaf people from hearing families in Bristol (Woll 1983). New signs had replaced these older forms, with the colour signs having an identical manual form that was differentiated solely by mouthing the equivalent English words for 'brown', 'green' etc.

Sutton-Spence, Woll and Allsop (1990) conducted a major investigation of sociolinguistic variation in BSL fingerspelling, using a dataset of 19,450 fingerspelled items collected from 485 interviews with BSL signers on the deaf television programme See Hear. They analysed the use of the British manual alphabet in relation to four social factors: sex, region, age and communication mode used. There were no significant effects due to gender on the use of fingerspelling, but age was significant. In the data from those aged 45 years or older, Sutton-Spence and her colleagues found that over $80 \%$ of all clauses included a fingerspelled element. In comparison, fingerspelling was used in fewer than $40 \%$ of clauses in the data from participants under 45. Region was also an important variable: most fingerspelling was found in the 
signing of individuals from Scotland, Northern Ireland, Wales and the Midlands, with the least used by signers from Southwest England. Deaf individuals who used simultaneous communication (i.e., speaking and signing at the same time) also used significantly more fingerspelling than those who used signed communication alone.

In BSL, these age-related differences in fingerspelling usage undoubtedly reflect the educational experiences of older deaf people, many of whom were instructed using approaches that emphasised the use of fingerspelling. Language attitudes may also play a role here, with older people possibly also retaining stronger negative attitudes towards sign language use, although this has not yet been the focus of any specific empirical study.

The sociolinguistic variation study as part of the BSL Corpus Project revealed that variation in the BSL lexical variants for colours, countries and numbers is systematically conditioned by social characteristics, especially age (Stamp et al., 2015). Figure 2 below, for example, shows the signs six to nine that represent the most common variants in two English cities: Birmingham and London.

Figure 2. Birmingham and London number signs

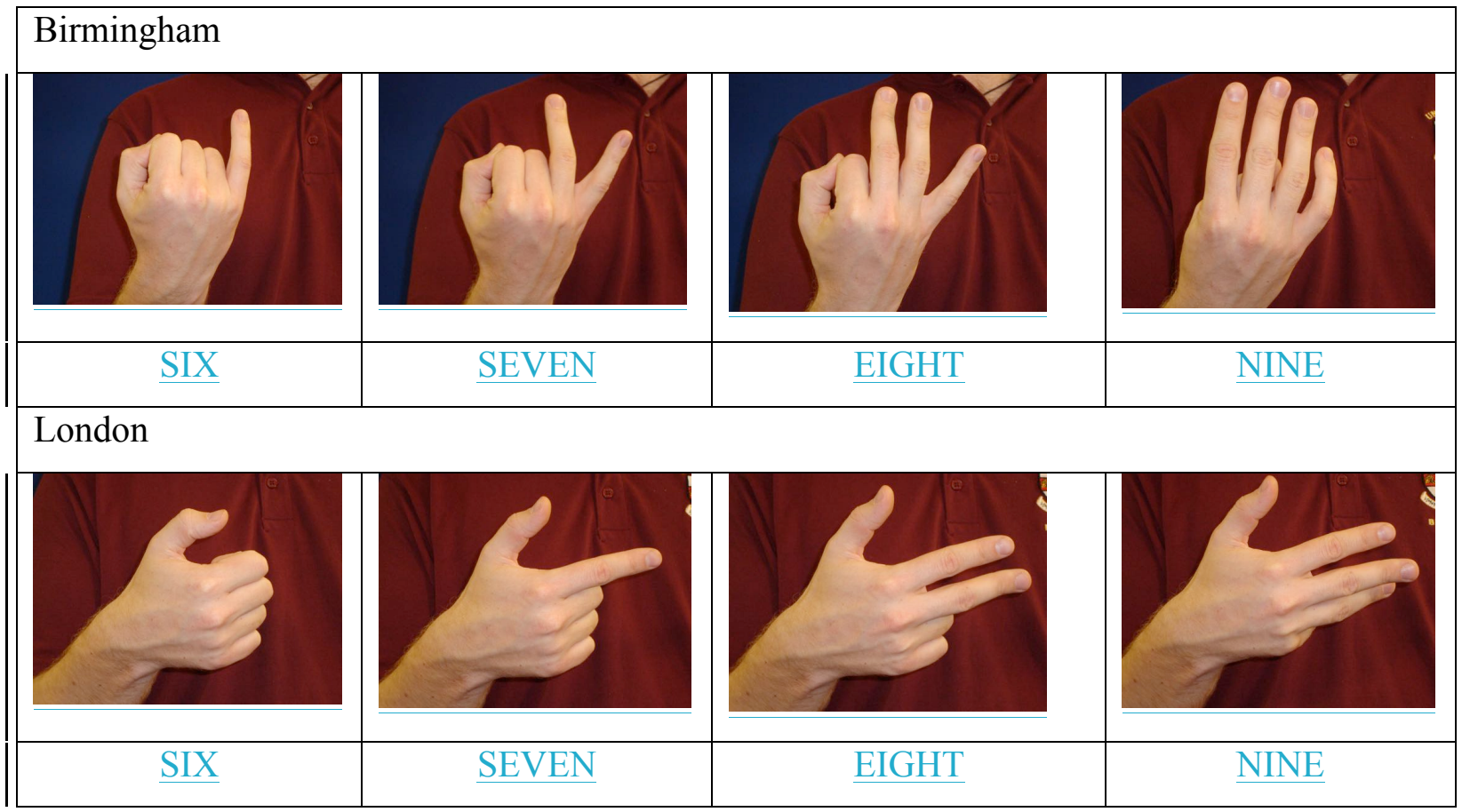

Multivariate analyses of this data revealed that age has the strongest effect on variation in colour, number, and country signs with older signers strongly favouring the use of traditional regional variants compared to younger signers. Further analysis 
revealed a significant difference between the younger and middle-aged groups in the use of number signs, indicating a dramatic change between these generations in the use of traditional variants. Also school location (whether they attended a local school or one from another part of the UK) and language background (whether participants had deaf signing parents or not) were significant. Those who were educated locally favoured the use of traditional signs compared to those who were educated outside of the region where they reside. Participants with hearing parents disfavoured the use of traditional signs, while those with deaf parents favoured the use of traditional signs.

A recent project drawing on data from six of the cities in the BSL Corpus investigated age and regional differences in fingerspelling patterns in both nonnativised fuller fingerspellings (which involve fully spelling out English borrowings using the manual alphabet) and nativised fingerspelling-based signs (which involve abbreviations and other modifications of fingerspelled words so that these more closely fit into the phonology of BSL) (Brown \& Cormier, submitted). This study showed that English signers differed in fingerspelling patterns compared to those from Scotland and Northern Ireland. Glasgow and Belfast residents favoured nonnativised fingerspelling production compared to signers in London, Birmingham, Manchester and Bristol. In addition, for Glasgow and Belfast, age is also a significant predictor for favouring non-nativised fuller fingerspellings, particularly for those aged over 60 years. This suggests a language change in progress in the use of fingerspelling. In London and to a lesser extent Birmingham, there is a marked preference for using single manual letter fingerspelled signs. In future, it would be interesting to conduct ethnographic investigations to find out which of these fingerspelling patterns signers are aware of, their attitudes towards fingerspelling, and how these relate to social factors.

\section{Gender}

There have not yet been any empirical studies demonstrating systematic lexical variation in any BSL variety due to gender. There have, however, been studies reporting the existence of other types of gender variation. In terms of conversational interaction, for example, Coates and Sutton-Spence (2001) claimed that female BSL signers in their dataset tended to set up a collaborative conversational floor, while 
males signers generally took control of the floor one at a time and use fewer supportive back-channelling strategies.

In a follow up study, however, Fenlon, Schembri and Sutton-Spence (2013) failed to find any gender differences. They looked at 28 dyads, balanced for gender and age, taken from the BSL Corpus conversational data. Fenlon and his colleagues coded which signer had the floor, and any manual and non-manual (i.e., head-nods) backchannel strategies used. In an analysis of the duration and frequency of turns and manual backchannels, age, but not gender, was significant, with older signers taking longer turns and using manual back-channels with greater duration. Neither gender nor age were significant for non-manual back-channels.

\section{Ethnicity and religion}

Generally, there are no clearly identifiable distinctions in the sign language used by various ethnic groups in England, unlike what has been identified in deaf communities elsewhere (e.g., lexical variants used predominantly or exclusively by deaf African-American signers of ASL, see Lucas et al., 2001; McCaskill et al., 2016), partly because the education of deaf children in England has, for the most part, never been fully segregated by ethnicity or religion. Some older members of this community were educated in a separate Jewish deaf school that existed in London from 1866 to 1965 (Jackson 1990). A book of BSL signs used to represent key elements of Judaism was published in 2003. Catholic schools for deaf children were also established in England, such as St John's school in Leeds, and anecdotal reports suggest that the signing used in this school was quite distinct, but it is yet to the focus of any detailed investigation.

Many deaf people in England from other minority ethnic backgrounds are increasingly forming social groupings which combine their deaf and ethnic identity (for example, social groups formed by deaf people with south Asian backgrounds) and thus we might expect some sociolinguistic variation reflecting these identities to develop over time.

\section{Language contact and the lexicon}

A recent study using the BSL Corpus data investigated mouthings in conversation and spontaneous narratives in 1781 tokens of verb signs, collected from 100 participants 
in Glasgow, Belfast, London and Bristol (Proctor, 2016). Mouth actions form a key component of all sign languages, and fall into two categories: 'mouthings' and 'mouth gestures' which involve mouth actions unrelated to spoken language words. The study found gender and region to be significant, although the effects were not strong: female participants and signers from the English cities in the study produced more mouthing than males and signers from outside England. The regional differences support anecdotal observations about the relatively greater prevalence of mouthing in English varieties of BSL (compared to the data from Scotland, Northern Ireland and Wales), and may be partly due to relatively more emphasis on speech skills in English schools for deaf children. The gender difference may also reflect wider sociolinguistic trends in the English-speaking world, where women are more likely to use more prestige variants (Labov 2001). The influence of English and educational methods, however, remained to be explored in a more detailed ethnographic study.

\section{Phonological variation and change}

There has been only a little work on phonological variation in BSL varieties. Deuchar (1981) noted that phonological deletion of the non-dominant hand in two-handed signs was possible in BSL (sometimes known as 'weak drop', e.g., Brentari 1998). Deuchar claimed the deletion of the non-dominant hand in symmetrical two-handed signs, such as GIVE and HOSPITAL, was frequent, as in ASL (Battison 1974). She also suggested that weak drop in asymmetrical two-handed signs appeared most likely in such signs where the handshape was a relatively unmarked configuration, such as B handshape (in which all the fingers are extended and held together flat) or S handshape (a fist). Thus, variants without the subordinate hand seemed more common in her data in signs such as RIGHT (with subordinate B) than in FATHER (subordinate H - in which only the index and middle fingers are extended from the fist handshape). Furthermore, she undertook a pilot study to investigate what social factors might affect the frequency of weak drop. Deuchar predicted that signers might use less deletion in less formal situations. She compared 30 minutes of BSL data collected under two situations: one at a deaf club social event and another in a church service. Based on a small dataset of 201 tokens, she found that only $6 \%$ of two-handed signs occurred without weak drop in the formal situation, whereas $50 \%$ exhibited deletion of the non-dominant hand in the informal setting. She also suggested that weak drop 
variation may also reflect language change in progress, based on Woll's (1981) claim that certain signs (e.g., AGAIN) which appear to be now primarily one-handed in modern BSL were formerly two-handed.

Glimpses of diachronic change in phonological structure emerged in the study of BSL numeral signs discussed above. Stamp et al. (2015) found that older people made significantly greater use of two-handed variants of number signs compared to younger signers. Language background was also important with signers from deaf families using more two-handed number signs compared to those from hearing families. Finally, gender was also found to be a significant factor with male signers favouring the use of two-handed number signs and female signers favoured the use of onehanded number signs. Stamp et al. (2015) suggest that this is indicative of a language change in progress. This finding adds to the growing observation across unrelated sign languages that there is a shift from two- to one-handed signs (e.g., McKee et al., 2009). The study also revealed that women are using more one-handed forms than men. If we regard the shift from two- to one-handed forms as a language change in process, then we might conclude that women are leading this change in accordance with Labov's ‘change from below’ principle II (Labov 2001).

The BSL Corpus Project team also conducted an investigation into phonetic variation in BSL signs produced with a ' 1 ' handshape - a hand configuration in which only the index finger is extended from the fist (Fenlon et al., 2013). Using 2110 tokens collected from spontaneous signed discourse involving 211 signers from 7 urban centres across the UK, multivariate analyses revealed that handshape variation in these signs is constrained by linguistic factors such as the handshape of the preceding and following sign (i.e., there was evidence of assimilation/co-articulation of handshape), the grammatical category of the sign (with pronominal signs showing the most variation), and lexical frequency (with the highest frequency signs showing the most variation in handshape). Only one social factor appeared to be significant: region. Within England, participants from Bristol appeared to make relatively greater use of variation in the 1 handshape, compared to participants from London and Birmingham. Manchester signers were least likely to display variation in the 1 handshape. These results were surprising, as they seem to suggest subtle differences in the phonetics of handshape variation in different regions across England. Regionally-based phonetic differences like these have not been reported for BSL before, and more work is needed to understand if we have any evidence here for the 
emergence of regional 'accents' in BSL.

\section{Syntactic variation and change}

There has been little research into syntactic variation in BSL varieties, and there have not yet been studies demonstrating whether there are grammatical differences between individual signers due to gender, age, social class or region (although differences due to age of acquisition have been investigated, see Cormier et al, 2012).

There has been some speculation that increased access to English (e.g., in the provision of captioned television) and growing influence from hearing, non-native signers in the British deaf community may, for example, be leading to an attrition of heritage BSL signing (Turner 1995), but no work has as yet been conducted on syntactic change in any BSL variety. Many authors have, however, noted the existence of English-influenced varieties of signed communication in the BSL community (e.g., Sutton-Spence \& Woll, 1999). Deuchar (1984) suggested that BSL and signed English varieties exist in a diglossic relationship, building on a similar account first proposed by William Stokoe (1969) for ASL, with signed English as the high prestige variety used in formal situations. As explained above, Deuchar's research involved the collection of data both from hearing and deaf participants, as well as native and non-native signers. She identified a more English-like variety of signing used in church services, primarily found in the signing of the hearing missioners but also among some deaf individuals. This variety incorporated a lot of fingerspelling, and lexical items followed English word order. It also lacked typical BSL morphosyntactic patterns, such as extensive topicalisation, exclusively nonmanual marking of negation and interrogatives and spatial modifications of signs. While recognising that such variation exists and that it may be partly situational in nature, there has been some debate about whether it is best characterised as a diglossic situation, and indeed whether this model is at all appropriate for the current social situation in deaf communities (e.g., Lee 1982, Deuchar 1984, Lucas \& Valli 1992). English is no longer tied exclusively to some social situations-BSL has become the language of instruction in some schools for deaf children (whereas English remains the language of instruction in most schools), for example, and is used in nationally broadcast television programmes. Woll, Allsop and Sutton-Spence's (1991) work showed a dramatic shift away from simultaneous communication (spoken English 
together with sign) to BSL varieties among deaf people appearing on the See Hear programme during the $1980 \mathrm{~s}$ : from $52 \%$ of all communication in 1981 to only $12 \%$ in 1987. More formal varieties of BSL appear to exist, although how they structurally differ from more informal varieties has not yet been the subject of any specific research.

The BSL Corpus Project team investigated variation and change in a subset of BSL verbs, known as indicating verbs (Fenlon et al., accepted). These verbs can be directed towards locations in space associated with their arguments, and the focus of the study was to investigate under what circumstances this directionality was used. Their findings suggest that modification of indicating verbs in BSL is a pointingbased reference-tracking system with a number of linguistic factors predicting whether or not signs are modified directionally. There was, however, no evidence of an interaction with social factors in their data and they concluded that there is little to suggest that the use of space is becoming grammaticalised in BSL as part of an ongoing change in progress (unlike what has been reported for other sign languages, e.g., Padden et al. 2010).

\section{Conclusion}

In this chapter, we have explored some of the research conducted in the past few decades on sociolinguistic variation in BSL varieties in England. We have shown how, just as the 'first wave' of sociolinguistic research on spoken language communities has also done (Eckert, 2012), variation is often not random, but is conditioned by linguistic and social factors. Although our understanding has grown since the beginning of the BSL Corpus Project, much work remains to be done. The major sociolinguistic studies of BSL to date have covered a number of different regions in each country, but have not yet examined any particular region's deaf community to the same depth that is common in sociolinguistic studies of spoken languages. Moreover, many urban centres were not included in these studies (e.g., Liverpool, Sheffield and Leeds) and no rural sites were visited in England, for example, as part of the BSL Corpus Project. Other sociolinguistic variables need to be investigated (e.g., the influence of English language contact on word order, for example), and stylistic factors need to be more fully explored. The influence of immigrant communities, and the impact of the many late learners and second- 
language users on BSL is also important. All of this work could contribute to a 'second' and 'third wave' of sign language sociolinguistics, in which the social meaning of variation and change, and its relationship to identity, could be explored more fully. Pursuing such research questions will increase our knowledge about the sociolinguistics of sign languages, as well as broaden our understanding of variation and change in language generally.

Aronoff, Mark, Meir, Irit, Padden, Carol A., and Sandler, Wendy (2003). Classifier constructions and morphology in two sign languages. In Karen Emmorey (ed.), Perspectives on classifier constructions in sign languages, 53-84. Mahwah, NJ: Lawrence Erlbaum Associates.

Battison, Robbin (1974). Phonological deletion in American Sign Language. Sign Language Studies, 5: 1-19.

Brennan, Mary (1992). The visual world of BSL: an introduction. In David Brien (ed.), Dictionary of British Sign Language/English, 1-133. London: Faber \& Faber. Brentari, Diane (1998). A prosodic model of sign language phonology. Cambridge, MA: MIT press.

Brien, David (ed.). (1992). Dictionary of British Sign Language/English. London: Faber \& Faber.

Brown, Matt and Cormier, Kearsy (submitted). Sociolinguistic variation in the nativisation of BSL fingerspelling.

Bulwer, John (1644). Chirologia: Or the natural language of the hand. London: R. Whitaker. Bulwer, John (1648). Philocophus: Or the deafe and dumbe man's friend. London: Humphrey Moseley.

Carew, Robert (1602). Survey of Cornwall. London: John Jaggard.

Coates, Jennifer and Sutton-Spence, Rachel (2001). Turn taking patterns in deaf conversation. Journal of Sociolinguistics 2: 2-34.

Cormier, Kearsy, Schembri, Adam, Vinson, David and Orfanidou, Eleni (2012). First language acquisition differs from second language acquisition in prelingually deaf signers: evidence from sensitivity to grammaticality judgement in British Sign Language. Cognition 124(1): 50-65.

Deuchar, Margaret (1981). Variation in British Sign Language. In Bence Woll, J. G. Kyle and Margaret Deuchar (eds.), Perspectives on British Sign Language and deafness, 109119. London: Croom Helm. 
Deuchar, Margaret (1984). British Sign Language. London: Routledge and Kegan Paul. Eckert, Penelope (2012) Three waves of variation study: the emergence of meaning in the study of sociolinguistic variation. Annual Review of Anthropology 41: 87-100.

Elton, Frances and Squelch, Linda (2009). British Sign Language: London and South-East signs. London: Lexisigns.

Fenlon, Jordan, Schembri, Adam and Cormier, Kearsy. (accepted). Modification of indicating verbs in British Sign Language: a corpus-based study. Language.

Fenlon, Jordan, Schembri, Adam, \& Sutton-Spence, Rachel (2013). Turn-taking and backchannel behaviour in BSL conversations. Poster presented at the 11th Theoretical Issues in Sign Language Research Conference, University College London.

Fenlon, Jordan, Schembri, Adam, Rentelis, Ramas, and Cormier, Kearsy (2013). Variation in handshape and orientation in British Sign Language: The case of the ' 1 ' hand configuration. Language and Communication 33(1): 69-91.

Green, Francis (1783). Vox oculis subjecta. London: B. White.

Groce, Nora E. (1986). Everyone here spoke sign language: hereditary deafness on Martha's Vineyard. Cambridge, MA: Harvard University Press.

Jackson, Peter W. (1990). Britain's deaf heritage. Edinburgh: Pentland.

Jewish Deaf Association (2003). Sign language in Judaism. London: Jewish Deaf Association.

Johnston, Trevor (1989). Auslan: The sign language of the Australian deaf community. Unpublished doctoral dissertation, University of Sydney, Sydney.

Johnston, Trevor (2004). W(h)ither the deaf community? Population, genetics, and the future of Australian Sign Language. American Annals of Deaf, 148(5): 358-375.

Johnston, Trevor (ed.) (1998). Signs of Australia: A new dictionary of Auslan. Sydney: North Rocks Press.

Kegl, Judy. A., Senghas, Annie, and Coppola, Marie. (1999). Creation through contact: Sign language emergence and sign language change in Nicaragua. In Michel DeGraff (ed.), Language creation and language change: Creolization, diachrony and development, 179-237. Cambridge, MA: MIT Press.

Kyle, James G., and Woll, Bencie (1985). Sign language: the study of deaf people and their language. Cambridge: Cambridge University Press.

Kyle, Jim, and Allsop, Lorna (1982). Deaf people and the community. Bristol, UK: University of Bristol, School for Education: centre for Deaf Studies.

Labov, William (2001). Principles of Linguistic Change: Social Factors. Oxford, Blackwell. 
Ladd, Paddy (2003). Understanding deaf culture: in search of Deafhood. London: Multilingual Matters.

Lee, Dorothy M. 1982. Are there really signs of diglossia? Re-examining the situation. Sign Language Studies, 35:127-152.

Lucas, Ceil and Valli, Clayton (1992). Language contact in the American deaf community. San Diego: Academic Press.

Lucas, Ceil, Bayley, Robert and Valli, Clayton (2001). Sociolinguistic variation in American Sign Language. Washington, DC: Gallaudet University Press.

Lucas, Ceil, Bayley, Robert, Reed, Ruth, and Wulf, Alyssa (2001). Lexical variation in African American and white signing. American Speech, 76(4): 339-360.

McCaskill, Carolyn, Lucas, Ceil, Bayley, Robert and Hill, Joseph C. (2016). The hidden treasure of Black ASL: Its history and structure. Washington DC: Gallaudet University Press.

McKee, David, McKee, Rachel and Major, George (2011). Numeral variation in New Zealand Sign Language. Sign Language Studies 11 (5): 72-97.

Padden, Carol, Meir, Irit, Sandler, Wendy and Aronoff, Mark (2010). The grammar of space in two new sign languages. In Brentari, Diane (ed.), Sign languages, 570-92. New York: Cambridge University Press.

Proctor, Heidi. (2016). Sociolinguistic variation in mouthings in the BSL Corpus. Unpublished MSc dissertation, University College London.

Royal Commission (1889) On the education of the blind, deaf and dumb. London: HMSO. Royal National Institute for the Deaf (1981). Sign and say. London: RNID.

Schein, Jerome D. (1968). The deaf community: studies in the social psychology of deafness. Washington DC: Gallaudet College Press.

Schembri, Adam and Johnston, Trevor (2013). Sociolinguistic variation and change in sign languages. In Bayley, Robert, Cameron, Robert and Lucas, Ceil (eds.), Oxford Handbook of Sociolinguistics, 503-524. Oxford: Oxford University Press.

Schembri, Adam, Cormier, Kearsy, Johnston, Trevor, McKee, David, McKee, Rachel, and Woll, Bencie (2010). Sociolinguistic variation in British, Australian and New Zealand sign languages. In Brentari, Diane (ed.), Sign languages, 479501. Cambridge: Cambridge University Press.

Schembri, Adam, Fenlon, Jordan, Rentelis, Ramas, Reynolds, Sally and Cormier, Kearsy (2013). Building the British Sign Language Corpus. Language 
Documentation and Conservation, 7: 136-154.

Smith, Willaim H. (1989). The morphological characteristics of verbs in Taiwan Sign Language. Unpublished doctoral dissertation, Indiana University.

Stamp, Rose, Schembri, Adam, Evans, Bronwen and Cormier, Kearsy (2016) British Sign Language (BSL) regional varieties in contact: Investigating the patterns of accommodation and language change. Journal of Deaf Studies and Deaf Education 21(1): 70-82

Stamp, Rose, Schembri, Adam, Fenlon, Jordan and Rentelis, Ramas (2015). Variation and change in British Sign Language number signs. Sign Language Studies, 15 (2): $151-181$.

Stamp, Rose, Schembri, Andrew, Fenlon, Jordan, Rentelis, Rentelis, Woll, Bencie and Cormier, Kearsy (2014). Lexical variation and change in British Sign Language. PLoS ONE 9(4):e94053.doi:10.1371/journal.pone.0094053

Stamp. Rose (2016). Do signers understand regional varieties of a sign language? A lexical recognition experiment. Journal of Deaf Studies and Deaf Education 21(1): 83-93

Stokoe, William C. (1969). Sign language diglossia. Studies in Linguistics, 21: 27-41.

Stone, Christopher and Woll, Bencie. (2008). Dumb O Jemmy and others: Deaf people, interpreters and the London courts in the 18th and 19th centuries. Sign Language Studies 8(3): 226-240.

Sutton-Spence, Rachel and Woll, Bencie (1999). The linguistics of British Sign Language: An introduction. Cambridge: Cambridge University Press.

Sutton-Spence, Rachel, Woll, Bencie, and Allsop, Lorna (1990). Variation and recent change in fingerspelling in British Sign Language. Language Variation and Change, 2: 313330.

Turner, Graham H. (1995). Contact signing and language shift. In Heleen Bos and Gertrude M. Schermer (eds.), Sign language research 1994: Proceedings of the Fourth European Congress on Sign Language Research, Munich, September 1-3, 1994, $211-$ 230. Hamburg: Signum Press.

Tylor, Edward B. (1874). Researches into the early history of mankind. London: Murray. Watson, James (1809). Instruction of the deaf and dumb. London: Darton and Harvey. Woll, Bencie (1981). Borrowing and change in BSL. Paper presented at the Linguistics Association of Great Britain Autumn Meeting, York.

Woll, Bencie (1983). Historical change in British Sign Language. Bristol: University of 
Bristol.

Woll, Bencie (1987). Historical and comparative aspects of BSL. In James G. Kyle (ed.), Sign and school, 12-34. Clevedon, U.K.: Multilingual Matters.

Woll, Bencie, Allsop, Lorna and Sutton-Spence, Rachel (1991). Variation and recent change in British Sign Language: Final report to the ESRC. Bristol: University of Bristol.

Woll, Bencie, Sutton-Spence, Rachel, and Elton, Frances (2001). Multilingualism: The global approach to sign languages. In Ceil Lucas (ed.), The sociolinguistics of sign languages, 8-32. Cambridge: Cambridge University Press.

Woll, Bencie. (1994). The influence of television on the deaf community in Britain. In Inger Ahlgren, Brita Bergman and Mary Brennan (Eds.), Perspectives on sign language usage: Papers from the Fifth International Symposium on Sign Language Research, 293-301. Durham, UK: International Sign Linguistics Association.

\section{BIOGRAPHICAL NOTE}

Adam Schembri is a lecturer in sociolinguistics at the University of Birmingham, and co-editor (with Ceil Lucas) of 'Sociolinguistics and Deaf communities', published with Cambridge University Press. Rose Stamp is a postdoctoral fellow at the University of Haifa, and has published research into variation and change in British Sign Language. Jordan Fenlon is a lecturer in British Sign Language at HeriotWatt University, and has worked on a number of studies drawing on the British Sign Language Corpus data. Kearsy Cormier is Reader at University College London, and director of the British Sign Language Corpus Project.

\footnotetext{
${ }^{\mathrm{i}}$ Sections of this chapter has been adapted from the following two publications: Schembri and Johnston (2013) and Schembri et al. (2010).

iihttps://www.ons.gov.uk/peoplepopulationandcommunity/populationandmigration/populationestimates /bulletins/2011 censusquickstatisticsforenglandandwales/2013-01-30

iii Glosses of signs are generally represented with the use of upper case letters in the sign language linguistics literature.

${ }^{\text {iv }}$ http://www.bslcorpusproject.org

${ }^{v}$ Video clips of the regional variants for all of these 41 items can be found on the BSL Signbank website: http://bslsignbank.ucl.ac.uk/regional/
} 